\title{
El derecho a la verdad y su contribución a la memoria colectiva
}

\author{
John Charney Berdichewky*
}

\begin{abstract}
RESUMEN
Este artículo analiza la capacidad del derecho a la verdad para contribuir al esclarecimiento de la verdad histórica y a la construcción de la memoria colectiva tras períodos de violencia excepcional. Para hacerlo distingue dos dimensiones de este derecho. La primera es aquella que busca reconstruir el pasado mediante el proceso penal, identificando responsables y resarciendo el daño ocasionado a las víctimas. La segunda se refiere a un conjunto de prácticas y normas que buscan consolidar el respeto a la memoria colectiva por medio de la producción y circulación de discursos acerca del pasado en la esfera pública. El propósito es demostrar que mientras la primera dimensión privatiza una práctica (la construcción de la memoria colectiva) que es esencialmente política, la segunda hace que dicha práctica sea posible.
\end{abstract}

Derecho a la verdad - memoria colectiva - justicia transicional - libertad de expresión

\section{The Contribution of the Right to Truth to collective memory}

\begin{abstract}
This paper examines the right to truth's capacity to contribute to the discovery of historical truth and to the construction of collective memory after periods of exceptional violence. In order to do this, it distinguishes two dimensions of this right. The first one aims at reconstructing the past through criminal justice, identifying perpetrators and providing remedies to victims. The second
\end{abstract}

* Licenciado en Ciencias Jurídicas y Sociales, Universidad de Chile. Abogado. Doctor en Derecho, King's College London, Inglaterra. Profesor de Derecho Constitucional, Pontificia Universidad Católica de Valparaíso. Correo electrónico: john.charney@pucv.cl

Las ideas contenidas en este artículo fueron presentadas por primera vez en un conversatorio referido al derecho a la memoria, organizado por el Centro de Estudios Aurora de la Escuela de Derecho de la Pontificia Universidad Católica de Valparaíso. Agradezco a Benjamín Valladares por su invitación y por todos los comentarios y sugerencias que en esa oportunidad recibí. En una versión más elaborada, el artículo fue presentado en el programa de magíster de Derecho de la Universidad de Valparaíso. Agradezco a Jaime Bassa por invitarme y a todos quienes generosamente criticaron algunas de sus propuestas. Agradezco finalmente las valiosísimas y constructivas sugerencias de dos evaluadores anónimos. Esta investigación se enmarca en el Proyecto Fondecyt de Iniciación No 11181088.

Artículo recibido el 2 de enero de 2019 y aceptado para su publicación en este número el 1 de agosto de 2019 
consists on a number of practices and norms that aim to consolidate respect to collective memory through the production and circulation of discourses about the past in the public sphere. The purpose is to demonstrate that while the first dimension privatizes an essential political practice (the construction of collective memory) the second one make this practice possible.

Right to truth - collective memory - transitional justice - freedom of expression

\section{INTRODUCCIÓN}

$\mathrm{E}$ 1 modo en el que una comunidad política codifica su memoria, es decir, el soporte que utiliza para reproducirla en el tiempo, define en una medida importante la forma en que esa comunidad va a procesar y se va a relacionar con su pasado. El derecho a la memoria -que ha jugado un rol determinante en la construcción de la memoria colectiva a partir de la segunda mitad del siglo XX-surge y se proyecta en el mundo occidental como consecuencia del intento del nazismo de exterminar al pueblo judío durante la Segunda Guerra Mundial ${ }^{1}$. La Declaración Universal de los Derechos Humanos de 1948 afirma en su Preámbulo que "el desconocimiento y menosprecio de los derechos humanos ha originado actos de barbarie ultrajantes para la conciencia de la humanidad". Por esta razón llama a todos los pueblos y naciones a esforzarse por promover "mediante la enseñanza y la educación, el respeto a estos derechos y libertades y asegura[r], por medidas progresivas de carácter nacional e internacional, su reconocimiento y aplicación universales y efectivos". Quienes ven en estas palabras un reconocimiento de la importancia que la memoria histórica tiene en la protección de los derechos humanos creen también en la necesidad de dotarla de resguardos jurídicos que la proyecten en el tiempo y que prevengan el resurgimiento del terror desatado por los sistemas totalitarios o autocráticos ${ }^{2}$.

Las "leyes de la memoria" buscan hacerse cargo del legado dejado por la represión, la violencia y las violaciones sistemáticas a los derechos humanos planeadas, administradas y ejecutadas por el aparato estatal en los períodos más oscuros de la historia. Estas leyes son la consecuencia de la reflexión colectiva acerca de un pasado violento y buscan conciliar los términos de la convivencia, restaurar una identidad política fracturada y restablecer su normal funcionamiento ${ }^{3}$. Aunque el objeto del recuerdo, tratándose de la

${ }^{1}$ Quien articula por primera vez el concepto de memoria colectiva es Maurice Halbwachs. La tesis central de Halbwachs es que a los agentes colectivos es posible atribuirles memoria, por cuanto el recuerdo requiere, necesariamente, de los otros. La memoria no sería así el producto de la intuición sensible del individuo que conserva ad eternum la identidad del objeto recordado. Por el contrario, la memoria sería el producto del contexto social, Halbwachs, 1992. Surge y se nutre "de corrientes que poseen una realidad objetiva fuera de nosotros" y que definen el contenido del objeto del recuerdo. El contexto social no solo permite o hace posible que un individuo recuerde. Desde la perspectiva de Holbwachs, la comunidad misma está dotada de una memoria colectiva que le permite desarrollar un profundo sentido de su propia identidad. RICEUR 2008, p. 159.

${ }^{2}$ Luther, 2010, p. 57.

${ }^{3}$ Millard, 2014, p. 147 
construcción de la memoria colectiva, está íntimamente asociado con los hechos históricos que le sirven de base, es que las leyes de la memoria tienen una estrecha relación con la búsqueda de la verdad. En el sistema internacional de los derechos humanos esta relación ha dado origen al denominado derecho a la verdad ${ }^{4}$. En este artículo se distinguirán y abordarán separadamente dos aspectos de este derecho. El primero consiste en aquel que busca establecer la verdad respecto de las circunstancias en que ocurrieron los hechos de violencia y esclarecer su significado ético y político, busca determinar la responsabilidad de los perpetradores y procura obtener el resarcimiento de los daños sufridos por las víctimas y sus familiares. El segundo es lo que la literatura ha denominado el deber de recordar y consiste en un conjunto de normas y prácticas que buscan consolidar la memoria colectiva mediante la rememoración de fechas históricas, la creación de museos de la memoria y la criminalización de la negación o justificación (primero) de la shoab y (luego) de otros genocidios y violaciones sistemáticas a los derechos humanos. El primer aspecto de este derecho ha sido abordado fundamentalmente por la justicia penal, pero también ha tenido un importante desarrollo en la jurisprudencia de las Cortes internacionales de derechos humanos en la determinación de responsabilidades estatales. El segundo aspecto se ha materializado con hitos rememorativos y prácticas discursivas que buscan regular la producción de discursos en la esfera pública. A pesar de sus diferencias, ambos han sido defendidos como mecanismos que contribuyen al esclarecimiento de la verdad histórica y que facilitan el proceso de construcción de la memoria colectiva.

El punto de partida de este artículo es que el derecho a la verdad en su primera dimensión -el esclarecimiento de los hechos históricos y su comprensión por medio de la justicia penal- no cuenta con herramientas suficientes para abordar y procesar el legado de la violencia excepcional. La justicia penal, como se analizará en la primera sección, no solo tiene problemas para atribuir responsabilidad cuando se ha producido una inversión radical de las condiciones morales mínimas de punibilidad. Además, la justicia penal reduce el terror del pasado a una relación entre las partes y a la resolución de un aspecto puntual del pasado. Al privatizar la definición de una cuestión que es esencialmente política, tiende a normalizar el carácter fundacional de la violencia y con ello afecta la comprensión sobre el significado ético y político del terror. A pesar de lo anterior, el proceso penal puede contribuir a la determinación de ciertos hechos elementales de la historia, determinación que es fundamental para toda discusión posterior pertinente al significado de la violencia excepcional. La tesis con la que este artículo trabaja es que la comprensión del fenómeno del terror debe quedar entregada a lógicas deliberativas que caracterizan a la libertad de expresión, porque ellas permiten aglutinar la experiencia del sufrimiento, acumular los relatos y las vivencias que dan forma a la historia compartida y con esto es posible reconstruir una identidad política fracturada. Es con base en esta tesis que el artículo justifica -en la segunda y en la tercera sección- el derecho

${ }^{4}$ Este derecho surge fundamentalmente de las iniciativas de justicia transicional desarrolladas en Latinoamérica a fines del siglo XX y comienzos del siglo XXI y ha tenido en la Corte Interamericana de Derechos Humanos a uno de sus principales promotores, Naftali, 2017, p. 70. Para un análisis en detalle, véase Dulitzky, 2017; Ferrer, 2016; Campisi, 2014; Garibian, 2014. 
a la verdad en su segunda dimensión. El propósito es demostrar que esta dimensión del derecho - a diferencia de lo que sostiene parte de la literatura- contribuye a reforzar las prácticas deliberativas que son fundamentales para el proceso de construcción de la memoria colectiva en períodos transicionales.

\section{El ESCLARECIMIENTO DE LA VERDAD HISTÓRICA Y SU SIGNIFICADO}

Los órganos del sistema interamericano de derechos humanos han reconocido y desarrollado sistemáticamente el derecho a la verdad ${ }^{5}$. La jurisprudencia de la Corte Interamericana (en adelante la Corte) ha sido especialmente relevante en su delimitación conceptual y en la identificación de sus límites y funciones. En este contexto, el derecho a la verdad surge como una respuesta a la falta de esclarecimiento, investigación, juzgamiento y sanción de desapariciones forzadas y al consecuente esfuerzo de la Corte y de la Comisión Interamericana de Derechos Humanos (en adelante la Comisión) para que los Estados cumplan con su obligación de enjuiciar y sancionar a los perpetradores, de asegurar la debida reparación a los familiares de las víctimas y de establecer la verdad de lo ocurrido, identificando el destino y paradero de las víctimas e informándolo a sus familiares ${ }^{6}$.

Desde un punto de vista conceptual, la Corte ha vinculado el derecho a la verdad a la lucha contra la impunidad, al reconocimiento de las garantías judiciales y a la protección judicial. Así, ha sostenido que el derecho a la verdad se encuentra "subsumido en el derecho de la víctima o sus familiares a obtener de los órganos competentes del Estado el esclarecimiento de los hechos violatorios y las responsabilidades correspondientes, a través de la investigación y el juzgamiento que previenen los artículos 8 y 25 de la Convención"7. En un primer momento la Corte circunscribió este derecho a las víctimas y a sus familiares. Sin embargo, con el correr del tiempo, ha identificado que su ejercicio involucra una dimensión colectiva que atañe a la comunidad política en su conjunto. Ha señalado así que "el derecho a conocer la verdad tiene como efecto necesario que en una sociedad democrática se conozca la verdad sobre los hechos”. Dicho conocimiento "es una justa expectativa que el Estado debe satisfacer, por un lado, mediante la obligación de investigar las violaciones de derechos humanos y, por el otro, con la divulgación pública de los resultados de los procesos penales e investigativos" ${ }^{\text {. La }}$

${ }^{5}$ A nivel internacional, el derecho a la verdad se encuentra reconocido en la Convención Internacional para la Protección de todas las Personas contra las Desapariciones Forzadas, adoptada por la Asamblea General de las Naciones Unidas en diciembre de 2006. En su artículo 24(2) la Convención establece el derecho de las víctimas a "conocer la verdad sobre las circunstancias de la desaparición forzada, la evolución y resultados de la investigación y la suerte de la persona desaparecida". Para un estudio sobre el tratamiento del derecho a la verdad por la Corte Europea de Derechos Humanos véase Belavusau, 2015; Naftali, 2017 y en la Corte Interamericana de Derechos Humanos Ferrer, 2016; Dulitzky, 2017, CIDH, 2014.

${ }^{6}$ Corte IDH Caso Velásquez Rodríguez vs. Honduras, párr. 181.

${ }^{7}$ Corte IDH, Bámaca Velásquez, párr. 201.

${ }^{8}$ Corte IDH, Anzualdo Castro vs. Perú, párr. 119. 
dimensión colectiva del derecho a la verdad no solo busca preservar la memoria histórica sobre el pasado violento. Además (y relevante para el análisis que sigue más adelante) cumpliría una función preventiva, ya que, de acuerdo con la Corte, el esclarecimiento judicial de lo ocurrido contribuiría a evitar que hechos similares se repitan en el futuro 9 .

A pesar de la importancia que la Corte atribuye al derecho a la verdad, es consciente de sus límites y en especial de las dificultades que pueden surgir en tiempos de transición para conciliar la lucha contra la impunidad con la necesidad de esclarecer la verdad respecto de las circunstancias en que ocurrieron los crímenes. Collins sugiere que en Chile una perversa ventana de oportunidad para el esclarecimiento de la verdad se abrió entre 1998 y 2004 cuando los perpetradores, sujetos a la ley de amnistía, podían confesar sus crímenes para evitar cargos por secuestro permanente ${ }^{10}$. En ese sentido, la Corte ha entendido que muchas veces la verdad requiere de la implementación de medidas estatales que faciliten la obtención de información acerca del paradero y destino de las víctimas, como por ejemplo la aplicación de sanciones atenuadas a los perpetradores. Sin embargo, lo anterior no puede significar, de acuerdo con la propia Corte, que la obligación de investigar quede condicionada por actos o disposiciones normativas internas, cualquiera sea su naturaleza ${ }^{11}$. La significancia que la Corte atribuye a la investigación judicial la ha llevado a ser especialmente categórica al señalar que las leyes de amnistía, cuando se trata de graves violaciones a los derechos humanos, son contrarias a la Convención. No solo porque ellas promueven la impunidad y la indefensión de las víctimas, sino porque además impiden el acceso (de las víctimas, de sus familiares y de la sociedad en su conjunto) a la verdad en las circunstancias en que ocurrieron estas violaciones ${ }^{12}$.

Por otro lado, si bien la Corte ha reconocido que medidas extrajudiciales, en especial las Comisiones de Verdad, contribuyen al esclarecimiento de la verdad histórica, a la preservación de la memoria y a la determinación de las responsabilidades institucionales, políticas y sociales, en ningún caso considera que estas medidas puedan sustituir la investigación penal ${ }^{13}$. La primacía que el proceso penal ocupa en el esclarecimiento de la verdad histórica se basa en la relevancia que la Corte le atribuye en tres aspectos que si bien pueden separarse analíticamente, están íntimamente ligados en su jurisprudencia. El primero de ellos se refiere a la capacidad de la sentencia de reconstruir fácticamente un episodio de la historia y de determinar responsabilidades criminales. El segundo es de carácter ético y político y consiste en la valoración de los hechos en el marco conceptual de los derechos humanos. La sentencia judicial funcionaría como un reproche colectivo

${ }^{9}$ Corte IDH, Gudiel Álvarez y otros (Diario Militar) vs. Guatemala, párr. 51; Corte IDH, Ibsen Cárdenas e Ibsen Peña vs. Bolivia, parr. 66; Corte IDH, Anzualdo Castro vs. Perú, párr. 66; Corte IDH; Corte IDH, Padillo Pacheco vs. México, párr. 144.

${ }^{10} \mathrm{Al}$ respecto véase Collins, 2016, p. 133.

${ }^{11}$ Corte IDH, Masacres de Río Negro vs. Guatemala, párr. 190.

12 Corte IDH, Barrios Altos vs. Perú, párrs. 41-44; Gelman vs. Uruguay, párr. 229; Almonacid Arellano y otros vs. Chile, párrs. 105-114.

${ }^{13}$ Corte IDH Almonacid Arellano et al. v. Chile, parr 150; véase además Corte IDH Zambrano Vélez v. Ecuador, párr. 128. 
a quienes utilizaron el aparato estatal para perpetrar violaciones sistemáticas a los derechos humanos y también a quienes permitieron o dejaron pasar las atrocidades frente a sus ojos. Finalmente y como consecuencia de una verdad articulada por la investigación judicial y valorada en el marco conceptual de los derechos humanos, la Corte anuncia en su jurisprudencia una función preventiva general que reduciría exponencialmente el espacio para que los hechos investigados se repitan en el futuro ${ }^{14}$.

No cabe duda que los juicios producen un registro autorizado de las circunstancias en las que ocurrieron las violaciones a los derechos humanos. Sin embargo, la capacidad del derecho penal para lidiar con la violencia excepcional en contextos transicionales ha sido objeto de una crítica muy articulada. Su aspecto más débil es, quizás, el de la función preventiva. Fernando Atria aborda este problema a propósito de su análisis de la promesa del presidente Aylwin de que "nunca más" se repetirán en Chile las atrocidades de la dictadura. Su conclusión, a mi juicio correcta, es que el derecho simplemente no puede servir de garantía para esta promesa. El derecho no puede impedir el surgimiento de la violencia excepcional porque cuando eso sucede, el derecho mismo se ha suspendido, y ha perdido en consecuencia toda capacidad para contenerla ${ }^{15}$.

En un artículo reciente, Daniela Accatino presenta una defensa a la respuesta penal en contextos de transición que elude la crítica a la función preventiva del derecho penal. Siguiendo la teoría comunicativa de la pena de Anthony Duff, su defensa se enfoca en justificaciones de carácter ético-político que apuntan a la reconstrucción de una comunidad fracturada como consecuencia del pasado violento. De acuerdo con Accatino, la sentencia judicial constituye un agravio público de un acto "que ofende los valores básicos que definen a la comunidad política que por eso los juzga y condena"16. El agravio público no solo reafirmaría la condición de la víctima como perteneciente a una comunidad que busca reforzar su compromiso con aquellos valores compartidos y que fueron quebrantados durante el período de violencia excepcional. Además, por medio del llamado a responder de sus actos, esta comunicación también pretende tratar a los perpetradores como miembros pertenecientes a esa misma comunidad que se define "por los valores expresados en las normas quebrantadas" ${ }^{17}$. Es importante advertir que esta comunicación no se reduce a los perpetradores y a las víctimas. El carácter público del agravio hace del juicio un instrumento de reproche colectivo que reafirmaría valores compartidos por la comunidad y que al hacerlo posibilitaría la reconstrucción de su identidad política fragmentada por la violencia excepcional. La defensa comunicativa de la estrategia judicial, al tratarse de una teoría cuya justificación reside en el merecimiento del reproche dirigido al perpetrador, en cuanto agente moral responsable, es inmune, como ya se dijo, a las críticas y a la función preventiva del derecho penal. Sin

${ }^{14}$ Corte IDH, Ibsen Cárdenas e Ibsen Peña vs. Bolivia, parr. 66; Corte IDH, Anzualdo Castro vs. Perú, párr. 66; Corte IDH, Gudiel Álvarez y otros (Diario Militar) vs. Guatemala, párr. 51; Corte IDH, Padillo Pacheco vs. México, párr. 144. Véase además Dulitzky, 2017, p. 153.

15 Atria, 2003, p. 52.

16 Accatino, 2019, p. 8.

17 Accatino, 2019, p. 11. 
embargo es menos resistente a aquellas críticas que ponen en duda la capacidad del derecho penal para lidiar con situaciones en las que se ha producido una inversión radical de las condiciones morales mínimas de juzgamiento.

En Eichmann in Jerusalem, Arendt señala que cuando la normalidad política e institucional es remplazada por un Estado que se construye sobre la base de principios criminales, como el Tercer Reich, las categorías jurídicas dejan de funcionar. Dejan de hacerlo porque en esas circunstancias es el acto delictual el que se transforma en la regla legal y el acto no delictual en la excepción. En el postscript de Eichmann, Arendt se detiene en la figura de la obediencia debida, utilizada por la defensa de Eichmann, para demostrar los problemas de la aplicación de los conceptos jurídicos a circunstancias de terror excepcional. Esta figura, en circunstancias de normalidad política, exime de (o atenúa la) responsabilidad penal de un subordinado que comete un delito bajo la orden impartida por un superior. La Corte de Jerusalén, impugnando la aplicación de esta figura al caso de Eichmann, concluye que tratándose de órdenes manifiestamente criminales los subordinados no tienen la obligación de obedecer y deben representar la ilegalidad de la orden a su superior. El problema, en este caso concreto, es que las órdenes que Eichmann recibía de sus superiores se ajustaban perfectamente al marco normativo y administrativo que regía al Tercer Reich. No se trataban entonces de órdenes "manifiestamente ilegales” y, por tanto, de órdenes que Eichmann hubiese podido o debido representar. Para condenarlo en estos términos, lo que la Corte debió haber requerido de él no era que revisara si las órdenes de sus superiores se ajustaban a la legalidad existente, sino que si ellas se ajustaban a una buena conciencia y esto no es algo que un tribunal de justicia pueda exigir ${ }^{18}$. Vista así, la condena de Eichmann no responde a estándares ni precedentes legales, sino solo a la monstruosidad de sus actos ${ }^{19}$.

El problema de la atribución de responsabilidad penal por los crímenes cometidos durante períodos de terror excepcional es solo una manifestación de un problema más general que se refiere a la disparidad que existe entre la descripción del fenómeno jurídicamente delictivo y el fenómeno del terror. Así como señala Mañalich, "la circunstancia de que la descripción de los hechos constitutivos del terror como hechos delictivos sea verdadera no implica que esa sea la descripción verdadera del terror" ${ }^{20}$. Es este "déficit descriptivo" del derecho penal el que lleva a Agamben, a propósito de su reflexión acerca de Auschwitz, a sostener que:

es posible que sean los procesos (los doce procesos celebrados en Nuremberg, más otros que se desarrollaron dentro y fuera de las fronteras alemanas, hasta el de 1961 en Jerusalén, que concluyó con la muerte en la horca de Eichmann y abrió

${ }^{18}$ Esta exigencia se hace aún más exigua cuando el mal se mecaniza por medio del aparato burocrático del Estado. Arendt ve en Eichmann un eslabón más en una cadena de masacres administrativas, un eslabón que desprovisto de toda agencia pierde la capacidad de contradecir una estructura social que había sucumbido ante el poder de Hitler, Arendt, 2006a, p. 295.

19 Arendt, 2006a, p. 294. Para una crítica al argumento de Arendt, véase Norrie, 2017, pp. 124 y ss.

${ }^{20}$ Mañalich, 2010, p. 10. 
el camino a una nueva serie de procesos en la República Federal) los responsables de la confusión intelectual que ha impedido pensar Auschwitz durante decenios ${ }^{21}$.

El proceso judicial, según Agamben, no solo ha impedido aclarar el significado ético y político de lo ocurrido sino que además ha impedido la "simple comprensión humana de lo acontecido" 22 . Buena parte de su explicación se encuentra en la dificultad de trasladar al lenguaje -y más específicamente al lenguaje jurídico- una experiencia que parece no admitir verbalización. Agamben se concentra en la figura del testigo y en su imposibilidad de comunicar hechos que son "irreductibles a los elementos reales que lo constituyen"23. La magnitud del horror de Auschwitz pone al testigo frente a la imposibilidad de verbalizar, frente a la indecibilidad de un fenómeno que desmonta todas las categorías jurídicas y éticas existentes. Un fenómeno cuya materia "es refractaria a cualquier intento de determinar la responsabilidad... una alquimia en la que el bien y el mal y, junto a ellos todos los metales de la ética tradicional alcanzan su punto de fusión" 24 . Es por ello que los juicios de Nuremberg dejaron la impresión de que habían resuelto algo que no podían resolver, de que el problema se había superado, de que la verdad se había saldado. Sin embargo -advierte Agamben- el problema sigue siendo tan enorme que este pone en tela de juicio al propio derecho que intenta contenerlo ${ }^{25}$.

Un juicio similar es el que han sostenido Fernando Atria y Juan Pablo Mañalich a propósito del terror desatado durante la dictadura militar en Chile. De acuerdo con Mañalich, los juicios en contra de los militares no solo no han permitido comprender el fenómeno del terror en su real magnitud, sino que además naturalizaron la violencia fundacional sobre la que se construyó nuestra identidad política y, en ese sentido, distorsionaron la comprensión que tenemos de nosotros mismos ${ }^{26}$. De acuerdo con Atria, esto se debe a que el lenguaje de los derechos humanos, utilizado para juzgar a los perpetradores, no permite reproducir la radicalidad de la violencia excepcional y por eso cuando intenta hacerlo no solo termina banalizando el mal sino que además vulgariza al derecho ${ }^{27}$. Ambos coinciden en que uno de los principales problemas es que el derecho privatiza un asunto -el de la violencia excepcional- que es esencialmente colectivo y del que depende la identidad política que se forja tras el período del terror. Mediante

\footnotetext{
${ }^{21}$ Agamben, 2005, p. 18.

22 Agamben, 2005, p. 7.

23 Agamben, 2005, p. 9.
}

${ }^{24}$ Agamben, 2005, p. 20. Es necesario tener presente que si bien el terror se distancia del lenguaje y lo convierte en un fenómeno irreductible a las categorías jurídicas, Agamben es enfático al señalar que Auschwitz no es una realidad "absolutamente" separada del lenguaje. De ser así, se estaría comulgando, sin quererlo, con el nacionalsocialismo y con su propósito de borrar toda evidencia de los campos de exterminio. El punto es que el terror no puede ser reducido a categorías jurídicas. Agamben, 2005, p. 164. Para una propuesta acerca de cómo lidiar en contextos de justicia transicional con las dificultades del testimonio, véase Отто, 2016.

\footnotetext{
25 Agamben, 2005, p. 18.

${ }^{26}$ MaÑalich, 2010, p. 10.

27 Atria, 2003, p. 76.
} 
el juicio, el fenómeno del terror termina por reducirse a una "relación procesal", a un problema entre las partes en la que lo que interesa es determinar la "culpabilidad aislada que se expresa en el hecho punible respectivo" 28 y en el resarcimiento de los daños de las víctimas y sus familiares.

Privatizar la violencia excepcional significa, por un lado, que el terror de Estado queda diluido, en términos explicativos, al registrarse como un cúmulo de responsabilidades individuales por la desviación de estándares normativos. ${ }^{29}$ Vista así, la violencia excepcional se reduce a un catálogo de atrocidades que si bien puede mostrar la envergadura y sistematicidad de los crímenes, restringe el fenómeno del terror a un problema de agencia individual que impide ver con claridad su dimensión burocrática: la organización y utilización del aparato estatal para eliminar la disidencia política e imponer por la fuerza un nuevo orden de cosas. Esto tiene graves consecuencias políticas, ya que al reducir el conflicto a un cúmulo de responsabilidades individuales se normaliza la violencia fundacional que dio origen al pacto político surgido tras ella. Como previene Mañalich, cuando los crímenes son tratados como desviaciones individuales y excepcionales del ordenamiento jurídico $-\mathrm{y}$ no como el producto del uso sistemático del aparato estatal para la organización, administración y ejecución del terror con fines políticos- se purga de vicios el orden constituido y se consolida, paradójicamente, el triunfo definitivo del orden impuesto ${ }^{30}$.

La tesis de Accatino es que la dimensión comunicativa de la pena descarta el problema anterior. Lo haría porque a pesar de que la sentencia reduce el terror a responsabilidades por acciones de individuos, cada una de esas responsabilidades expresadas en la sentencia como "agravios públicos", constituye un llamado a responder por y a reprochar el quebrantamiento de valores colectivos ${ }^{31}$. Si la sentencia efectivamente produce tal efecto comunicativo, o si por el contrario, lo que queda es la sensación de un desplazamiento del terror a la esfera de las partes enfrentadas en juicio, no es algo que pueda resolver este artículo. Lo que sí es cierto es que el fenómeno de la privatización de la responsabilidad se agrava, así como ha sucedido en Chile, cuando no es el propio Estado, sino que las víctimas, sus familiares y las organizaciones de derechos humanos las que asumen el protagonismo en el impulso de la persecución penal por los crímenes cometidos durante la dictadura ${ }^{32}$. En estas circunstancias, la violencia excepcional se reduce a una disputa privada entre perpetradores y víctimas, una disputa en la que el resto de la comunidad se asoma como un espectador que a la distancia observa cómo los tribunales intentan reconstruir el pasado por medio de un pleito judicial, soslayando la significancia colectiva que la experiencia del terror tiene en la reconstrucción de la identidad de la comunidad política.

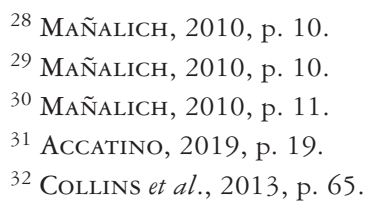


Las críticas a la estrategia judicial en contextos de transición vistas aquí comparten un mismo diagnóstico respecto de la dificultad de traducir el fenómeno del terror al lenguaje del derecho. Que el lenguaje de los derechos humanos sea insuficiente para dar cuenta de la violencia excepcional, o que el derecho trivialice -al privatizar- un conflicto que es esencialmente colectivo o que las condiciones mínimas de punibilidad se inviertan radicalmente durante el terror -son razones que se han dado para explicar que el derecho carece de herramientas suficientes para permitir la comprensión de la violencia excepcional-. Por ello es que cuando intenta hacerlo, genera un déficit explicativo del terror que impacta en el proceso de reconstrucción de una identidad política fragmentada.

Al presentar estas críticas no quiero insinuar que el proceso judicial no tenga incidencia alguna en la búsqueda de la verdad en contextos de justicia transicional. La discusión acerca de las dificultades del proceso penal para aclarar el significado de los hechos históricos no niega la existencia de estos hechos y la posibilidad de que el proceso penal sea capaz de contribuir a su esclarecimiento aun cuando tenga dificultades para hacer lo mismo respecto de su significado. Incluso Agamben hace una distinción entre las "circunstancias históricas" del exterminio y su "significado ético y político" y reconoce que las primeras han sido suficientemente aclaradas por la literatura especializada ${ }^{33}$. Aunque el proceso penal tiene dificultades para aclarar el significado del terror, puede contribuir -idealmente con el apoyo de otros instrumentos como las Comisiones de Verdad- a la determinación de los hechos -y muy especialmente- de aquellos a los que Arendt se refiere como hechos "brutalmente elementales de la historia" 34 y que serán objeto de atención en la próxima sección. Estos se refieren a cuestiones que tienden a darse por establecidas de manera transversal en una comunidad política, como por ejemplo, que La Moneda fue bombardeada el 11 de septiembre de 1973 en una acción conjunta de las Fuerzas Armadas. No solo la sentencia judicial contribuye a reunir y resguardar las pruebas que acreditan la ocurrencia de estos hechos. Además, el derecho, como se argumentará en la próxima sección, debe proteger estos hechos de intentos de tergiversación o negación para reforzar las prácticas deliberativas en torno al significado de la verdad histórica y a la construcción de la memoria colectiva.

\section{EL DEBER DE RECORDAR}

El segundo aspecto del derecho a la verdad, así como se indicó más arriba, busca consolidar el respeto a la memoria colectiva. De acuerdo con Millard, se refiere a "un conjunto de normas y políticas públicas destinadas, especialmente en sociedades que establecen una forma democrática de gobierno, [... ] a dar cuenta de las violaciones a los derechos humanos que han precedido" ${ }^{35}$. Su contribución a la memoria colectiva no

\footnotetext{
33 Agamben, 2005, p. 7.

34 ARENDT, 2006b, p. 234.

35 Millard, 2014, p. 145.
} 
consiste en recabar información acerca de hechos históricos mediante la investigación judicial. Por el contrario, por medio de un conjunto de instituciones, normas y prácticas que incluyen la rememoración de fechas históricas; la creación de museos de la memoria; y la criminalización del negacionismo histórico, entre otros, regula la producción y circulación de discursos respecto del pasado en la esfera pública.

El negacionismo histórico ha sido el fenómeno que más discusión ha generado en la literatura a propósito de la segunda dimensión del derecho a la verdad. Este se refiere a la negación sistemática e ideológica de la verdad y de la realidad y el término se empleó por primera vez para designar aquellas teorías que niegan la existencia de cámaras de gas en los campos de concentración nazis ${ }^{36}$. El negacionismo de la shoah rechaza, además, el número de personas asesinadas por los nazis, niega que la solución final al problema judío consistiera en su exterminio y agrega que la evidencia que da cuenta de lo anterior no es otra cosa que la historia contada por los vencedores. Acompañado del desarrollo de las tecnologías, el fenómeno del negacionismo se ha expandido por las redes sociales y sitios de internet y múltiples países han reaccionado haciendo de él un ofensa criminal. ${ }^{37}$ Francia fue el primer país en tipificarlo como un delito criminal en 1990, seguido por Austria, Alemania, Bélgica y España. Hoy el delito de negacionismo no solo ha sido incorporado a nivel internacional sino que se ha expandido para cubrir hechos distintos a la $s h o a b^{38}$. Actualmente en Chile se encuentra en tramitación en el Congreso un proyecto de ley de memoria histórica que, entre otras cosas, sanciona criminalmente el negacionismo y la justificación del golpe de Estado del 11 de septiembre de $1973^{39}$.

Así como la primera, la segunda dimensión del derecho a la verdad también ha sido criticada por las dificultades que el derecho tendría para procesar la violencia excepcional. En esta sección presentaré una de tales críticas. Ella ve en las leyes de la memoria la imposición de una versión hegemónica de la historia que restringe indebidamente la libertad de expresión. Escéptica acerca de la posibilidad de encontrar una verdad intersubjetiva del pasado, esta crítica prefiere dejar la discusión histórica absolutamente abierta y sujeta a las reglas de lo que llama "la ética de la libertad de expresión”. Tras mostrar los problemas de esta teoría -fundamentalmente el hecho de que pone en riesgo la integridad de hechos históricos elementales para la comprensión política del pasado- y apoyado en La verdad y lo político de Fernando Atria, desarrollaré una defensa a la deliberación política como instrumento necesario para el desarrollo de la memoria colectiva. Esta defensa, a diferencia de la crítica anterior, refuerza la idea de que la verdad tiene un rol constitutivo en la identidad de una comunidad política y

\footnotetext{
${ }^{36}$ Rousso, 1994.

${ }^{37}$ FronZA, 2018, p. 10.

38 En la Unión Europea, la Decisión marco de 2008 relativa a la lucha contra determinadas formas y manifestaciones de racismo y xenofobia mediante el derecho penal, establece el deber de los Estados miembros de garantizar que se castiguen, entre otras conductas, la apología pública, la negación o la trivialización flagrante de los crímenes de genocidio, crímenes contra la humanidad y ciertos crímenes de guerra.

39 Véase Boletín No 9746-17.
} 
a base de tal verdad justifica la existencia de un marco institucional que promueva el respeto de la memoria colectiva.

\section{Posición 1: el escepticismo histórico}

Hay quienes ven en la progresiva expansión que las leyes de la memoria han tenido desde la segunda mitad del siglo XX, un intento por parte del Estado -o de entes supraestatales- de controlar el pasado para articular un imaginario colectivo que refuerce su hegemonía ${ }^{40}$. Así es vista por Uladzislau Belavusau la conmemoración de fechas históricas, la construcción de museos de la memoria y, muy especialmente, los delitos de negacionismo y justificación de la shoab-que con el tiempo se han expandido para sancionar los genocidios y las violaciones sistemáticas de los derechos humanos ${ }^{41}$-. Desde la perspectiva de Belavusau, estas leyes no solo no logran esclarecer nuestra comprensión del pasado sino que imponen un punto de vista que distorsiona y transforma la realidad social en distintos niveles. En primer lugar, reforzarían la versión judía del arrepentimiento -que supone que solo las víctimas pueden perdonar a los perpetradores- frente a los rituales cristianos del olvido. Además, crearían una versión dicotómica de la Segunda Guerra Mundial que atribuye toda responsabilidad a los nazis y a sus colaboradores y venera plenamente a los vencedores. Esto último reforzaría las dicotomías de buenos/ malos y de víctimas/perpetradores que caracterizan los relatos de la Segunda Guerra Mundial. Además, estas leyes reforzarían la idea de la democracia militante que niega protección constitucional a los discursos que incitan al odio. Todo esto -que Belavusau define como la "monumental prescripción legal de la verdad histórica"- habría contribuido a la articulación de la integración europea en torno a un relato que se basa en el temor a repetir las atrocidades del pasado ${ }^{42}$.

El argumento de Belavusau se nutre de una concepción particular acerca de la verdad y de la historia. En Truth and Truthfulness, Bernard Williams observa la existencia de dos grandes corrientes de ideas que predominan en el pensamiento y en la cultura moderna. Ambas tienen algo relevante que decir acerca de la verdad. Williams asocia la primera al sentido común, pero también a la comprensión científica o positivista del mundo. Desde esta perspectiva la verdad es la correspondencia entre un juicio o una afirmación determinada y el objeto al que esta o aquella se refiere. Afirmaciones o juicios formulados bajo esta concepción de la verdad pueden ser generalmente aprobados o rechazados ${ }^{43}$. Desde una perspectiva histórica esta concepción se vincula a la idea de objetividad, la que alude a una creencia sobre la realidad del pasado y ve en la verdad

\footnotetext{
${ }^{40}$ Al respecto véase Garibian, 2008; Mälksoo, 2009; BARAhona, 2011; LÖYtÖм ̈̈KI, 2014.

${ }^{41}$ Literatura jurídica acerca de la criminalización del negacionismo, véase, entre otros HarE et al., 2011; Behrens, 2017; FronZa, 2018.

42 Belavusau, 2015, pp. 539-541.

43 Williams, 2002, p. 1.
} 
una correspondencia con esa realidad ${ }^{44}$. La segunda corriente expresa un compromiso intenso con la veracidad o, como señala Williams, un intenso afán por no ser engañado y por identificar los motivos reales que se esconden tras las apariencias. La sospecha generalizada de los motivos que mueven las acciones de las personas, especialmente en el plano político, se proyecta hacia un descreimiento o escepticismo de la idea misma de la verdad, la que muchas veces se toma como una cuestión relativa o subjetiva. Desde una perspectiva histórica esta corriente proyecta su escepticismo hacia afirmaciones del pasado generalmente concebidas como verdaderas, las que tiende a identificar -en cambio- como posiciones ideológicas o autointeresadas ${ }^{45}$.

Es con esta segunda corriente escéptica con la que es posible identificar el argumento de Belavusau. Su argumento apunta a un interés político relevante que consiste en evitar que el Estado manipule el pasado mediante una verdad "oficialmente construida” con el propósito de acrecentar su poder hegemónico. La libertad de expresión contribuye, en efecto, a evitar ese riesgo. Sin embargo, cuando ella se construye sobre fundamentos que se escinden de la búsqueda de la verdad, puede producir efectos tan graves como aquellos que intenta evitar. Belavousau establece conexiones relevantes entre los discursos que intentan articular el pasado, el presente y el futuro, por una parte, y los intereses políticos que tras esos discursos se esconden, por la otra. Lo que se pretende es dilucidar "cómo, quiénes, a través de qué medios, con qué intensión y con qué fin transforman [algunas de] las experiencias del pasado en asuntos políticamente relevantes" ${ }^{46}$. La premisa central de esta perspectiva es que la historia y la historiografía no son más que instrumentos puestos al servicio de quienes intentan satisfacer sus propios intereses políticos y que la esfera pública es el espacio en el que esos intereses se enfrentan con el propósito de alcanzar la hegemonía sobre el discurso del pasado. En esta lucha compiten las "versiones oficiales" de la historia con versiones alternativas. Mientras que las primeras intentan conservar la legitimidad de los proyectos políticos vigentes, las segundas intentan subvertirlos.

Desde este punto de vista, las leyes de la memoria no hacen otra cosa que clausurar la deliberación política, codificando la versión hegemónica de la historia que da legitimidad al sistema político imperante. No es de extrañar entonces que quienes se aproximan al fenómeno de la memoria colectiva desde esta perspectiva prefieran dejar la discusión concerniente al pasado plenamente abierta y se opongan a cualquier intento de fijar la verdad por medio de museos de la memoria, delitos de negacionismo y conmemoración de fechas históricas, entre otros. Según Belavusau, "la historiografía usualmente funciona como un agente de poder que delimita la 'verdad oficial' y se hace cargo del trauma colectivo". La única solución disponible es la de dejar la deliberación entregada a lo que él llama "la ética de la libertad de expresión". De lo contrario, advierte, la represión de

${ }^{44}$ Evans, 1999, p. 252. Para un análisis de los conceptos de la verdad en el campo de la memoria colectiva véase EAGLESTONe, 2004, pp. 137 y ss.

45 Williams, 2002, p. 1.

${ }^{46}$ Meyer, 2008, p. 176. 
versiones alternativas de la historia podría generar sentimientos de inferioridad y concitar la violencia del pasado que la propia "historia oficial" pretende aplacar ${ }^{47}$.

La libertad de expresión aparece así como la alternativa ideal para hacerse cargo del trauma y para reconstruir una identidad política fragmentada por la violencia del pasado. Sin embargo, para alcanzar estos fines la libertad de expresión no puede escindirse de la búsqueda de la verdad, como parece desprenderse del argumento de Belavusau ${ }^{48}$. Si lo hace no solo arriesga la posibilidad de construir un significado intersubjetivamente validado del pasado violento, sino que además arriesga, como se verá más adelante, la integridad de los hechos que constituyen ese pasado y que son fundamentales para hacer posible cualquier discusión pertinente al sentido de la violencia excepcional en una comunidad política. Afirmar que la verdad juega un rol fundamental en el proceso de construcción de la identidad política de una comunidad en contextos transicionales equivale a decir que hay una respuesta de la interpretación del pasado que, desde una perspectiva política, es correcta. Por lo mismo, su renuncia es equivalente a vivir en el engaño. Lo que Mañalich sostiene respecto de cualquier argumento que defiende el olvido es aplicable a cualquier argumento que renuncia a la verdad: "equivale a un alegato a favor de una forma de comunidad que renuncia a registrar el hecho de su fractura y de la contingencia de su eventual reconstitución, es decir, a favor de una comunidad estructurada sobre una falsa conciencia" ${ }^{49}$.

El modo en el que Belavusau aborda la relación entre el presente y el pasado y las premisas en las que construye su argumento no parecen dejar espacio para una deliberación que se articule en torno a una verdad que pueda ser validada intersubjetivamente. Si la verdad no es otra cosa que la imposición de una versión del pasado para la satisfacción de los intereses políticos de quienes la imponen, todos los discursos políticamente articulados en torno a ella deben ser descartados. Es por ello que la ética de la libertad de expresión que Belavusau defiende parece incapaz de hacer distinciones relevantes entre las posiciones que se enfrentan en la esfera pública. No solo no permite distinguir entre los discursos que condenan las violaciones sistemáticas a los derechos humanos de aquellos que las justifican -e incluso de aquellos que las niegan-. Tampoco puede hacer distinciones relevantes entre la más burda de las falacias del pasado y las más rigurosa de las investigaciones históricas. Y estas distinciones, como se sostendrá, son fundamentales para la reconstrucción de la identidad política tras períodos del terror.

En lo que sigue se darán dos pasos adicionales para demostrar la importancia que la verdad ocupa en la discusión pública respecto de la violencia excepcional. En el primero, se verá que la verdad funciona como un ideal regulativo que permite orientar la discusión en torno al significado de la violencia excepcional en la construcción de la identidad de la comunidad política. El segundo, analizará la importancia de resguardar

47 Belavusau, 2015, p. 556.

${ }^{48}$ Para la relación entre la verdad y la libertad de expresión en el pensamiento político moderno véase Haworth, 1998; Charney, 2018.

${ }^{49}$ MaÑalich, 2010, p. 45. 
ciertos "datos brutalmente elementales de la historia" como condición necesaria para que la discusión sobre el significado de la violencia excepcional sea posible.

\section{Posición 2: la verdad como constitutiva de las prácticas políticas}

A diferencia de Belavusau, Atria cree firmemente en la existencia de una verdad intersubjetivamente válida y además cree que esa verdad es constitutiva de las prácticas políticas de una comunidad. Es precisamente la existencia de esa verdad lo que permitiría, según él, distinguir por medio de razones deliberativamente articuladas, aquellas decisiones que en política pueden ser consideradas objetivamente correctas de aquellas que no ${ }^{50}$.

Atria pisa un terreno minado. La relación entre la verdad y la política no es pacífica y la creencia generalizada es que ella es antitética. Mientras que invocar la verdad en la discusión política suele entenderse como el intento por imponer un punto de vista en desmedro del diálogo; invocar la deliberación política para decidir cuestiones cuya demostración ya ha pasado por la prueba de la razón (verdades racionales) o de la facticidad (verdades fácticas) es poner a la verdad en serio peligro. Una de las razones que explica la aparente desavenencia entre verdad y política, según Arendt, es que los modos por los que se comprueba o se verifica la verdad contienen cierto grado de compulsión, compulsión que estaría en contradicción con los modos de comunicación que caracterizan a la política. Enunciados como "El 11 de septiembre ocurrió un golpe militar en Chile"; "Dos más dos son cuatro"; "La tierra gira alrededor del sol”; o "El ser humano es un fin en sí mismo", requieren distintos modos de verificación, pero una vez que eso ocurre y que se pronuncian como verdades, ellas no admiten discusión, persuasión, acuerdo u opinión ${ }^{51}$. Es por eso que si el lenguaje de la verdad se traslada al de la política, la política se transformaría en otra cosa. A la inversa, y como se verá más adelante, si el debate, la opinión y la persuasión se llevan al terreno de las verdades, ellas también se ven seriamente amenazadas.

Si bien los modos de comunicación que caracterizan la búsqueda de la verdad están en tensión con aquellos que caracterizan a la política, lo cierto es que la verdad juega una función fundamental en la política y en especial -lo que aquí nos preocupa- en la construcción de la memoria colectiva. De acuerdo con Atria, "la verdad cumple una función constitutiva de prácticas deliberativas, en el sentido de que sin referencia a ella esas prácticas no pueden sino degenerar en prácticas opresivas" 52 . A primera vista, el argumento de Atria parece una inversión radical de los términos del argumento de Arendt. Mientras que para el primero, la verdad es la que explica la existencia de prácticas deliberativas en la política, para la segunda, la verdad tiende a destruir esas prácticas. Lo cierto es que las diferencias que separan a Atria de Arendt se disuelven

\footnotetext{
50 ATria, 2009.

51 ARENDT, 2006b, p. 235.

52 Atria, 2009, p. 27.
} 
cuando observamos que al hablar de la relación entre la verdad y la política, no solo están utilizando conceptos distintos de verdad, sino que además están hablando de dimensiones distintas de la política. Por ese motivo, y como se analizará más adelante, ambos argumentos son compatibles y por ello aplicables en conjunto con la construcción de la memoria colectiva.

Lo primero que es necesario destacar en el argumento de Atria es que la función de la verdad en la política está relacionada con los aspectos más elevados de la vida en común. Ella permite dilucidar el modo en el que hemos de entendernos como ciudadanos y en el que hemos de entender la comunidad política a la que pertenecemos. Parte importante del esfuerzo intelectual desarrollado por la filosofía política desde la Antigüedad ha sido el de responder estas preguntas. Y si bien se trata de preguntas filosóficas, son antes que nada preguntas políticas. Lo son porque la política, desde la perspectiva de Atria, no es otra cosa "que el espacio donde se encuentran ciudadanos a deliberar y decidir sobre lo que es bueno para todos" 53 . Es el espacio en el que se decide cómo debe ser vivida la vida en común. El punto central de Atria -y de ahí la conexión entre la verdad y la política- es que hay una respuesta correcta a estas preguntas y esas respuestas, esa verdad, desempeña un rol constitutivo de las prácticas políticas y deliberativas de esa comunidad. Asignarle a la verdad un rol constitutivo de nuestras prácticas políticas tiene como consecuencia que solo de este modo podemos entenderlas como prácticas que reconocen la agencia del otro. Según Atria, "[l]a razón por la que la verdad en sentido constitutivo tiene esta dimensión es que solo cuando ella es asumida podemos entender que al encontrarnos y deliberar sobre cómo hemos de vivir estamos apelando a algo común a todos" 54 . La existencia de una verdad intersubjetiva exige, en otras palabras, que quien la defienda debe ofrecer razones que sean comunes a todos para demostrar su existencia. A su vez, esta verdad exige aceptar las razones que el resto tenga que ofrecer. En ese sentido, la verdad es constitutiva de prácticas políticas que reconocen la dignidad del otro y que, a pesar de asumir la existencia de una posición correcta, excluye la opresión.

Llevado al terreno de la memoria, el argumento de Atria exigiría que la reconstrucción de la identidad colectiva tras la época del terror, se haga mediante prácticas políticas que reconozcan la agencia y dignidad de $\operatorname{todos}^{55}$. Como la deliberación es constitutiva de estas prácticas, podríamos decir que ellas deben sujetarse a lo que aquí se ha llamado la "ética de la libertad de expresión". Sin embargo, es necesario ser muy cuidadosos en este punto. El propósito de la deliberación no sería, desde la perspectiva de Atria, el de reconstituir una identidad política de modo tal que ella sea el equivalente a la suma de visiones y posiciones que cada miembro de la comunidad exprese libremente y a la que se llegue mediante una negociación que satisfaga los intereses de todas las "partes". El reconocimiento de la agencia del otro por medio de la deliberación propiamente política

53 ATria, 2009, p. 31.

54 ATria, 2009, p. 37.

55 Atria rechaza categóricamente la judicialización como solución a la violencia excepcional ATRIA, 2004 , pp. 70 y ss. 
a la que Atria se refiere, no permite tratar de manera equivalente cuestiones que no los son: este tipo de deliberación no podría condenar las violaciones sistemáticas a los derechos humanos en Chile y, a su vez, justificarlas por la espiral de violencia que se habría desatado a partir de los años 60, como lo hizo la "Mesa de Diálogo" 56 . Reconocer la dignidad de todos, en las circunstancias del terror, consiste, por el contrario, en:

ver a los victimarios como víctimas en algún sentido, i.e., como reducidos a objetos deshumanizados (aunque en otra forma) por su propia ilusión de controlar la fuerza excepcional. Y entonces aparece la dimensión refundacional de la reconciliación. La violencia excepcional es la violencia de esa hora que no es la del derecho, la violencia que surge cuando el poder desaparece... La reconciliación supone redescubrir el valor de lo político. Esto es particularmente importante hoy, cuando lo político cada vez más se concibe como un espacio de gerencia, de pura racionalidad de medios. Lo político a la luz de la reconciliación es lo que nos permite relacionarnos unos con otros como humanos, y de ese modo nos permite vivir como humanos, nos hace humanos ${ }^{57}$.

Nótese que la verdad aquí apela al significado ético y político de la violencia excepcional. Así como lo hace Agamben ${ }^{58}$, Atria identifica una zona gris, una zona en la que las concepciones éticas tradicionales dejan de funcionar, ya que el terror ejerce una influencia deshumanizadora que afecta tanto a víctimas como a victimarios y que remece a la comunidad política en su conjunto. Determinar el sentido de esto no puede quedar entregado al derecho, como se analizó en la primera sección de este artículo. Al igual que Belavusau, Atria defiende la importancia de entregar a las prácticas deliberativas la función de determinar el significado que la violencia excepcional tiene en la construcción de la identidad de la comunidad política que se forja tras ella. El mérito de su argumento, sin embargo, es que lo hace sin desprenderse de un concepto de verdad validada intersubjetivamente. Su argumento es productivo porque a diferencia de Belavusau, que reduce el enfrentamiento político al afán por imponer los intereses de unos por sobre los intereses de otros, Atria ve en tal enfrentamiento un esfuerzo por encontrar aquello que nos es común, aquello que nos identifica como comunidad política.

Eso que Atria llama verdad constitutiva no solo hace posible la deliberación política sino que además permite -a diferencia del clásico argumento liberal- hacer distinciones relevantes entre las expresiones que se ventilan en la esfera pública. En efecto, el propósito del debate no es que las partes se encuentren en sus diferencias, renunciando parcialmente a sus aspiraciones para que todas queden medianamente satisfechas por medio de un acuerdo que las identifique por igual. El punto tampoco es, como lo sugirió J.S. Mill en su clásico ensayo Sobre la libertad, que la verdad tiene múltiples caras y que

56 ATria, 2004, p. 69.

57 Atria, 2004, p. 74.

58 Agamben va más lejos al señalar que en Auschwitz incluso la víctima aparece como opresor en la figura del Sonderkommando, Agamben, 2005, p. 20. 
su integridad depende de que todas ellas sean debidamente expuestas ${ }^{59}$. El punto de Atria es que tratándose de la construcción de la identidad política de un pueblo, hay contenidos que apuntan a consolidar esa verdad mientras que hay otros que se distancian de ella. La deliberación permite identificar unos de otros, permite distinguir aquello que es correcto, de aquello que es incorrecto desde una perspectiva política y lo hace sin desmerecer la agencia moral de cada uno de los que participa en el debate.

El argumento de Atria reconoce que la tarea de reconstituir una identidad política fragmentada tras la violencia excepcional es una tarea eminentemente política. Es quizás la tarea más noble de la política. Su argumento reconoce, sin embargo, que las condiciones en las que vivimos hoy, las condiciones del mercado, no son propicias para el desarrollo de lo político, es decir, para que los miembros de una comunidad se reconozcan recíprocamente en el diálogo como iguales. En un eco en el que resuenan algunas intuiciones de Belavusau, Atria señala que la política se ha fragmentado porque ella es hoy el espacio que replica los modos de interacción del mercado donde los agentes negocian entre sí para maximizar sus intereses y preferencias. En estas condiciones, no hay referencia a aquello que nos es común, no hay referencia a la verdad, o esas referencias se hacen difusas o secundarias y se actúa políticamente solo (o principalmente) a base del autointerés. Y así la pregunta que surge es ¿cómo debemos entender la relación entre la verdad y la política, cuando las condiciones en las que ella se desarrolla no son aquellas que permiten que los miembros de una comunidad se traten como iguales mediante la deliberación en la esfera pública? De esta pregunta surge una adicional que se refiere a ¿cuáles serían las implicancias de esas condiciones en el ejercicio de la construcción de la memoria colectiva y en la función que la ética de la libertad de expresión ocupa en ella? En lo que queda de este artículo se abordarán estas preguntas y se concluirá que la deliberación en torno al significado de la violencia excepcional requiere que se resguarden ciertos "hechos brutalmente elementales" de esa historia violenta, hechos sin los que el tipo de discusión que Atria propone, no sería posible.

\section{Verdad y política en H. Arendt: el retorno al derecho}

Las preguntas formuladas encuentran en Arendt a una interlocutora ideal, porque su análisis acerca de la relación entre la verdad y la política no es abordado desde las más altas esferas de la política sino que desde sus rincones más oscuros. A diferencia de Atria que en La verdad y lo político analiza la verdad desde el punto de vista de la política y encuentra en la primera una función constitutiva de la segunda; Arendt en Truth and Politics analiza la política desde el punto de vista de la verdad y desde ese lugar no ve otra cosa que aquello que Atria critica ${ }^{60}$. En efecto, en este ensayo Arendt describe a

59 Mill, 2005, pp. 63-64.

${ }^{60}$ Sabido es por todos que la política ocupa en el pensamiento de Arendt un lugar fundamental y que ella es una esfera llena de grandeza y dignidad. La política es mirada desde esta otra perspectiva en Truth and Politics, porque como ella misma reconoce, la está mirando desde el punto de vista de la verdad, es decir, desde una perspectiva que le es externa (Arendt, 2006(b): 258). 
la política no como el espacio de encuentro en torno a aquello que nos es común, sino como un campo de batalla en el que se enfrentan intereses parciales y donde solo cuenta y abunda el placer, la codicia, el partidismo y las ansias de poder y de dominación ${ }^{61}$. La razón de por qué Arendt pone el foco en este aspecto de la política y no en su grandeza y dignidad, la razón de por qué ella decide "deformarla" de acuerdo con su propia concepción de la política se debe a que es precisamente en su punto más bajo donde se produce la colisión con la verdad. Lo interesante de su argumento, y que lo conecta con el argumento de este artículo, es que la verdad debe ser protegida de los aspectos más bajos de la política porque la verdad -y en este punto coincide con Atria- es constitutiva de la política. Si lo que buscamos, en definitiva, es resguardar aquello que le da grandeza y dignidad es necesario proteger a la política de sí misma ${ }^{62}$.

En principio podría resultar paradójico que si bien el punto de partida de las tesis de Atria y de Arendt sean idénticos (la verdad es constitutiva de la política) ambos lleguen a conclusiones tan radicalmente opuestas. En efecto, mientras que Atria ve una relación de necesidad entre la verdad y la política, Arendt rechaza esa conexión y sostiene que la verdad es una amenaza para la política. Estas diferencias no solo se deben, como ya se explicó, a que mientras Atria se refiere a la política desde su función más elevada, Arendt se refiere a ella desde su dimensión más miserable. Las diferencias se explican, además, por el concepto de verdad que uno y otro utilizan. Lo que Atria llama la verdad constitutiva no es otra cosa que la coherencia entre el fundamento de la política (el espacio donde los ciudadanos se encuentran a decidir cómo debe vivirse la vida en común) y los medios necesarios para alcanzarla (prácticas deliberativas). Por otro lado, el argumento de Arendt se enfoca en una manifestación muy concreta de la verdad: lo que ella llama la verdad factual. Así, su análisis acerca de la relación entre verdad y política es un análisis de la relación entre hechos y eventos históricos que son constitutivos de la identidad política de una comunidad, por un lado, y el terreno en el que se enfrentan las pasiones y los intereses más bajos que mueven la lucha por la conquista del poder y su permanencia en él. Mientras que desde la perspectiva de la memoria el concepto de verdad en Atria permite apelar a razones comunes para esclarecer el significado político del terror; el concepto de verdad en Arendt sirve de fundamento para resguardar verdades fácticas. Ambos se complementan, como se verá, porque la protección de las verdades fácticas hacen posible, en último término, la deliberación concerniente al sentido ético y político del terror y de su significado en la construcción de la identidad política de la comunidad.

El punto central de Arendt es que si la verdad factual es constitutiva de la política, es necesario resguardar la primera de los impulsos más bajos de la segunda, es decir, de su afán por alterar, tergiversar o suprimir hechos o eventos históricos de primera relevancia. Debe hacerlo, ya que son esas verdades las que hacen posible la existencia de una esfera compartida en la que los miembros de una comunidad puedan encontrarse como iguales a decidir cuestiones relevantes respecto de la vida en común. Aquellos hechos

\footnotetext{
61 Arendt, 2006b, p. 258.

62 Arendt, 2006b, p. 259.
} 
históricos que no pueden quedar entregados a la deliberación política y que deben ser excluidos de la discusión se refieren, indica Arendt, a "datos brutalmente elementales cuya indestructibilidad se ha dado por sentada incluso por los más extremos y sofisticados creyentes del historicismo" 63 . Para ilustrar el tipo de hechos que cabrían dentro de esta categoría, Arendt se refiere a una conversación que Clemenceau habría tenido hacia el final de su vida con un representante de la república de Weimar. En ella le preguntan su opinión respecto de quién será considerado por los historiadores como el responsable del inicio de la Primera Guerra Mundial. La respuesta de Clemenceau es que no lo sabe, sin embrago, lo que sí sabe de seguro es que no dirán que Bélgica invadió Alemania ${ }^{64}$.

¿Por qué sería necesario proteger ese tipo de verdades si ellas parecen en principio indestructibles? Deben protegerse, ya que a pesar de su apariencia, ellas son enormemente frágiles. Lo son, en primer lugar, porque a diferencia de las verdades racionales o de las verdades científicas que pueden ser demostradas, ya sea por medio de la argumentación o de la experimentación, las verdades fácticas no pueden ser reproducidas. Con la desaparición de las pruebas que acreditan su ocurrencia, desaparece también la posibilidad de reconstituirlas. Por lo mismo es que el paso del tiempo es un factor crítico para el resguardo de la evidencia histórica y, por tanto, de la memoria colectiva. Existe un umbral que separa la memoria formada por la experiencia biográfica de la generación que vivió el terror de las generaciones que la siguen. La única forma de preservar la memoria en el tiempo y de evitar que ella se pierda con la muerte de sus testigos, es darle una forma institucional ${ }^{65}$.

La verdad fáctica, por otro lado, es esencialmente contingente. Los hechos siempre pudieron haber ocurrido de un modo radicalmente distinto a como ocurrieron. Por eso es que un relato histórico puede ganar en coherencia cuando se distancia de la realidad y la ficción puede sonar, en ocasiones, más coherente que la realidad misma. Así, la verdad en toda su fragilidad se ve amenazada cuando se enfrenta a quienes utilizan la política como un instrumento para satisfacer su propia codicia, ansias de poder y de dominación. Si el fenómeno de las noticias falsas ha cobrado notoriedad en el último tiempo, no ha sido porque este sea un fenómeno nuevo ${ }^{66}$. La tergiversación de la realidad y la difusión de información falsa han sido herramientas largamente utilizadas por políticos inescrupulosos. Lo que estos políticos pretenden hacer creer es que su versión referente a determinados hechos es equivalente a una opinión. De ese modo mienten descaradamente y pretenden que esas mentiras queden amparadas por el derecho constitucional a la libertad de expresión. Un caso ilustrativo de lo anterior fue la declaración dada por Kellyanne Conway, Consejera del presidente Trump, cuando defendiendo una declaración falsa del Secretario de Prensa de la Casa Blanca, Sean Spicer, relativo al número de asistentes al acto de inauguración del Presidente de Estados Unidos, acuñó la expresión

\footnotetext{
63 Arendt, 2006b, pp. 234-35.

${ }^{64}$ Arendt, 2006b, p. 234.

65 Assmann, 2008, p. 113.

${ }^{66}$ VinNer, 2016.
} 
hechos alternativos para insinuar que, tal como sucede con la opinión, todos tienen el derecho (incluidas en este caso las autoridades) a expresar su propia versión de la realidad, aun cuando esa versión no tenga sustento alguno en la realidad que simulan describir.

La protección de la verdad frente al uso malicioso de la información es fundamental para garantizar la estabilidad de la propia esfera política. La circulación de información falsa en redes sociales y en medios de comunicación masivos no produce necesariamente, como lo señala Arendt, la sustitución de la verdad por la mentira ${ }^{67}$. Produce un efecto aún más dañino para la política: el cinismo. Cuando se pierde la confianza en el modo en que la esfera pública representa la realidad social comenzamos, poco a poco, a descreer de aquello que aparece ante los ojos de todos. Esta es la razón, dice Arendt, del porqué "la mentira permanente remueve el piso de nuestros pies y no proporciona nada en remplazo sobre lo que podamos pararnos" 68 . La esfera de la política, entendida ahora en su dimensión más noble y digna, no puede pretender incluir todo asunto relativo a la existencia humana. Ella encuentra su límite "en todas aquellas cosas que no pueden ser modificadas por la voluntad del hombre y solo respetando esos límites es que esta dimensión, donde somos libres para actuar y para producir cambios, puede permanecer intacta, preservando su integridad y manteniendo sus promesas" ${ }^{\circ 9}$.

Especialmente relevante es el cuidado de aquellos hechos históricos -aquellos brutalmente elementales- en los que se construye la memoria colectiva en períodos de transición. Estos hechos son inescindibles de la identidad de un pueblo que ha sido víctima del terror. Es por ello que cuando su configuración queda entregada al libre debate de ideas o a la negociación política, se está jugando con la propia identidad de ese pueblo. Su institucionalización por medio del derecho encuentra una justificación en el argumento de Arendt. Se trata de proteger, como ella lo afirma, datos de cuya certeza depende la propia estabilidad de una comunidad política. Es respecto de esos datos -y bajo el supuesto de su inalterabilidad-que toda otra discusión es posible, tanto en la esfera política como en la esfera social. Es en este punto donde el argumento de Arendt se encuentran con el de Atria. Si la verdad es constitutiva de las prácticas políticas lo es porque existe algo que es común a "nosotros" y que nos distingue de otros que no son miembros de nuestra comunidad. Sin la debida protección de esos datos brutalmente elementales de la historia, que son constitutivos de la identidad política de un pueblo, no es posible el tipo de deliberación política que Atria propone.

A modo de conclusión, es posible señalar las dificultades del derecho -y en particular las del proceso penal- para articular el significado ético y político de la violencia excepcional. El derecho tiene problemas para traducir a su lenguaje el fenómeno del terror, puesto que este desconfigura radicalmente las categorías éticas y jurídicas tradicionales. La investigación judicial puede, sin embargo, contribuir a proporcionar un registro oficial que de cuenta de ciertos datos brutalmente elementales de la historia. El

\footnotetext{
${ }^{67}$ ARENDT, 2006b, p. 252.

68 ARENDt, 2006b, p. 253.

${ }^{69}$ Arendt, 2006b, p. 259.
} 
derecho debe, además, resguardar esos datos porque de ellos depende la posibilidad de cualquier discusión que se dé acerca del significado que la violencia excepcional tiene en la construcción de la identidad política de una comunidad tras el período del terror. Aunque no ha sido el propósito de este artículo identificar mecanismos en particular para resguardar la verdad factual de la que habla Arendt, sí ha sido el de justificar, en general, leyes que rememoran fechas históricas, que crean museos de la memoria y que desincentivan expresiones que niegan la ocurrencia de estos hechos. Estas medidas refuerzan el proceso político, ya que orientan las prácticas discursivas de una sociedad hacia el esclarecimiento de aquella verdad que le es constitutiva.

\section{BiBLIOGRAFÍA}

Accatino, Daniela, 2019: “¿Por qué no a la impunidad? Una mirada desde las teorías comunicativas al papel de la persecusión penal en la justicia de transición”, Política Criminal 14 (27).

Agamben, Giorgio, 2005: Lo que queda de Aushwitz, Valencia: Pre-Textos.

Aldana-Pindell, Raquel, 2004: “An Emerging Universality of 'Justiciable Victims' Rights in the Criminal Process to Curtail Impunity for State-Sponsored Crimes", Human Rights Quarterly 26 (3): 605-686.

Arendt, Hannah, 1970: On Violence, New York: Harcourt.

Arendt, Hannah, 2006a: Eichmann in Jerusalem: A Report on the Banality of Evil, London: Penguin. Arendt, Hannah, 2006b: Between Past and Future, London: Penguin.

Assmann, Jan. 2008: "Communicative and Cultural Memory", en Astrid Erll y Ansgar Nünning (editores), Cultural Memory Studies, Berlin/New York: de Gruyter, 109-118.

Atria, Fernando, 2003: "La hora del derecho: los 'derechos humanos' entre la política y el derecho”, Estudios Públicos 91.

Atria, Fernando, 2004: "Violencia excepcional a través de ojos normales", en Roberto Saba (editor), Violencia y Derecho, Sela 2003, Buenos Aires: Editores del Puerto, 39-78.

Atria, Fernando, 2009: "La verdad y lo político (I): La verdad en su dimensión constitutiva", Persona y Sociedad 23 (1): 21-50.

Barahona, Alexandra; GonzÁlez-Enríquez, Carmen y Aguilar, Paloma, 2001: The Politics of Memory and Democratization, Oxford: Oxford University Press.

Behrens, Paul; Terry, Nicholas y Jensen, Olaf (editores), 2017: Holocaust and Genocide Denial: A Contextual Perspective, Oxon: Routledge.

Belavusau, Uladzislau, 2015: "Memory laws and freedom of speech: Governance of history in European law", en András Koltay, Comparative Perspectives on the Fundamental Freedom of Expression (editor), Budapest: Wolters Kluwer, 535-556.

Bernales, Gerardo, 2016: "El derecho a la verdad", Estudios Constitucionales 14 (2): 263-304.

Campisi, María, 2014: "From a Duty to Remember to an Obligation to Memory? Memory as Reparation in the Jurisprudence of the Inter-American Court of Human Rights", International Journal of Conflict and Violence 8 (1): 62-74.

Collins, Cath, et al., 2013: "Verdad, justicia y memoria por violaciones de derechos humanos en tiempos de dictadura, a 40 años del golpe militar", en Informe Anual sobre Derechos Humanos en Chile, Santiago: Universidad Diego Portales.

Collins, Cath, 2016: "Human Rights Defense in and trhrough the Courts in (Post) Pinochet Chile", Radical History Review, Issue 124. 
Comisión Interamericana de Derechos Humanos, 2014: "Derecho a la verdad en América", Documentos oficiales, disponible en www.cidh.org.

Charney, John, 2018: The Illusion of the Free Press, Oxford/Portland: Hart Publishing.

Dulitzky, Ariel, 2017: Derechos humanos en Latinoamérica y el sistema interamericano: Modelos para (des)armar, México: Universidad Nacional Autónoma de México.

Eaglestone, Robert, 2004: The Holocaust and the Postmodern, Oxford: Oxford University Press.

ENGLE, Karen et al., 2016: Anti-Impunity and the Human Rights Agenda, Cambridge: Cambridge University Press.

Evans, Richard, 1997: In Defense of History, London: Granta Books.

Ferrer, Eduardo, 2016: "The Right to the Truth as an Autonomous Right Under the InterAmerican Human Rights System”, Mexican Law Review 9 (1): 121-139.

FronZa, Emanuela, 2018: Memory and Punishment: Historical Denialism, Free Speech and the Limits of Criminal Law, La Haya: Asser Press.

Garibian, Sévane, 2008: "Taking Denial Seriously: Genocide Denial and Freedom of Speech in the French Law”, Cardozo Journal of Conflict Resolution 9 (2): 479-88.

Garibian, Sévane, 2014: "Ghosts Also Die: Ressisting Disappearance through the 'Right to Truth' and the Juicios por la Verdad in Argentina”, Journal of International Criminal Justice $12(3), 1-24$.

GonZÁlez, Eduardo y VARney, Howard (editores), 2013: Truth Seeking: Elements if Creating an Effective Truth Commission, New York: International Center for Transitional Justice.

Haworth, Alan, 1998: Free Speech, Oxon: Routledge.

Halbwachs, Maurice, 1992: On Collective Memory, Chicago: The University of Chicago Press.

Hare, Ivan y Weinstein, James (editores), 2009: Extreme Speech and Democracy, Oxford: Oxford University Press.

LÖYтöмÄKI, Stiina, 2014: Law and the Politics of Memory: Confronting the Past, Oxon: Routledge.

LUTHER, Jörg, 2010: "El derecho a la memoria como derecho cultural del hombre en democracia", Revista Española de Derecho Constitucional 89 (mayo-agosto), 45-76.

MÄLKsoo, María, 2009: "The Memory Politics of Becoming European: The East Europeans Subalterns and the Collective Memory of Europe". European Journal of International Relations 15 (4), 653-80.

Mañalich, Juan Pablo, 2010: Terror, pena y amnistía, Santiago: Flandes indiano.

Meyer, Erik, 2008: "Memory and Politics", en Astrid Erll y Ansgar Nünning (editores), Cultural Memory Studies, Berlin/New York: de Gruyter.

Mill, J.S, 2005: On Liberty, New York: Cosimo Classics.

Millard, Eric, 2014: “¿Por qué un derecho a la memoria?”, Revista Derecho del Estado 32 (enerojunio): $145-156$.

Naftali, Patricia, 2017: "The 'Right to Truth' in International Law: The 'Last Utopia'?”, en Uladzislau Belavusau y Aleksandra Gliszczynska-Grabias (editores), Law and Memory: Towards Legal Governance of History, Cambridge: Cambridge University Press, 70-88.

Norrie, Alan, 2017: Justice and the Slaughter Bench: Essays on Law's Broken Dialectic, Oxon: Routledge.

Отто, Diane, 2016: "Impunity in a Different Register: People's Tribunals and Questions of Judgement, Law and Responsibility", en Karen Engle, Zinaida Miller y D.M. Davis (editores), Anti-Impunity and the Human Rights Agenda, Cambridge: Cambridge University Press.

PARK, Gloria, 2010: "Truth as Justice: Legal and Extralegal Development of the Right to Truth", Harvard International Review 31 (4), 24-7.

Riccur, Paul, 2008: La memoria, la historia, el olvido, Buenos Aires: Fondo de Cultura Económica. Rousso, Henry, 1994: The Vichy Sindrome, Cambridge MA: Harvard University Press. 
VINNER, Katherine, 2016: "How Technology Disrupted the Truth". Recuperado el 7 de diciembre de 2018 de https:/www.theguardian.com/media/2016/jul/12/how-technology-disrupted-the-truth. Williams, Bernard, 2002: Truth and Truthfulness: An Essay in Genealogy, Princeton/Oxford: Princeton University Press. 